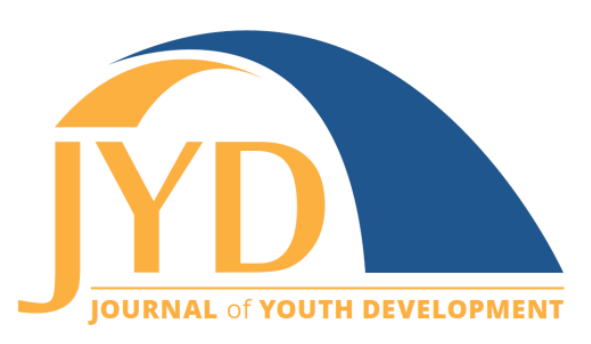

http://jyd.pitt.edu/ | Vol. 16 Issue 5 DOI 10.5195/jyd.2021.1187 | ISSN 2325-4017 (online)

\title{
Book Review: Roma Minority Youth Across Cultural Contexts: Taking a Positive Approach to Research, Policy, and Practice
}

\section{Richa Khanna}

Tata Institute of Social Sciences, Mumbai

richa.khanna@tiss.edu

\begin{abstract}
Roma Minority Youth across Cultural Contexts: Taking a Positive Approach to Research, Policy, and Practice is an important academic resource that has added to the scarce literature base on Roma culture. Through contributors from diverse backgrounds and utilizing relevant methodological approaches, the book bridges the gap between research and practice in the field of positive youth development (PYD), as applied to Roma youth. This text is an informative tool for students, practitioners, researchers, and policy makers from PYD and related fields.
\end{abstract}

Key words: Roma youth, positive youth development, cross-cultural psychology

The Roma community has been reported to be the most historically marginalized group in Europe. They have been subject to various forms of discrimination in the areas of education, social class, segregation, and access to resources and have faced other challenges while strengthening and honoring their unique identity, history, and culture (Dimitrova et al., 2021a). Roma Minority Youth across Cultural Contexts: Taking a Positive Approach to Research, Policy, and Practice not only lends a voice and visibility to traditionally underrepresented Roma youth, but it also places them front and center of policy and practice in the field of positive youth development (PYD). Broadly speaking, PYD is a positive psychology-based framework that emphasizes the role of strengths and resources in promoting well-being among youth (Dimitrova et al., 2021b).

Richard M. Lerner (2021), in his Foreword, offers a rich and nuanced conceptualization of Roma youth's developmental processes using a relational developmental systems meta-theory, which is based in individual $\Leftrightarrow$ context interactions. Radosveta Dimitrova, David Sam, and Laura

(c) $)_{\text {EY }}$ New articles in this journal are licensed under a Creative Commons Attribution 4.0 License. This journal is published by the University Library System, University of Pittsburgh and is cosponsored by the University of Pittsburgh Press. The Journal of Youth Development is the official peer-reviewed publication of the National Association of Extension 4-H Youth Development Professionals and the National AfterSchool Association. 


\section{Book Review: Roman Minority Youth}

Ferrer-Wreder (2021b), the book's editors, introduce readers to its distinguishing features as (a) the focus on a large and underrepresented ethnic minority group and (b) a strength-based conception of adolescence that sees all youth as having resources. The book is made up of three sections, with chapters written by expert contributors representing international, multidisciplinary, and multisectoral backgrounds.

Part A, comprised of three chapters, sensitizes policy makers and practitioners to the unique strengths and challenges faced by the Roma community, while also introducing ways of applying a PYD framework as a preventative intervention while working with Roma youth. It provides the reader with a comprehensive background on the Roma cultural context, including a history of their origin and migration, socialization processes, universality, and specifics pertaining to Roma youth and integration strategies employed by them. Part A also describes the PYD model's utility as applied to low-income Roma youth in the United States and the benefits of active involvement of Romani youth in early childhood education and care and promotion of positive identity development.

Part B, containing two chapters, serves as a commentary on theories pertaining to Roma adaptation and well-being. Although Western evidence-based approaches have predominantly guided PYD research, the authors acknowledge the need to consider the unique cultural realities of Roma youth. Theoretical and conceptual considerations on actualizing change with Roma youth and their communities have been discussed in depth. One chapter has been devoted to an overview of the research literature on Roma youth and their developmental trajectories and outcomes, future directions for research and policy on the positive development of Roma, and other ethnic minority youth groups.

The seven chapters of Part C comprise the most extensive of the three sections. This section offers empirical findings on PYD and well-being among Roma youth across diverse geographical locations including studies from Bulgaria, Kosovo, Albania, Romania, Hungary, and Serbia. These studies have collectively employed various research designs including qualitative (e.g., indepth interviews, participant observation-based research, content analysis), quantitative (e.g., cluster analysis, confirmatory factor analysis, linear regression), and mixed methods approaches to investigate PYD variables (school and family connectedness, school engagement and achievement, self-esteem, optimism, and ethnic identity, identity self-descriptors, internal and external developmental assets, thriving) covering both formal and informal educational settings. Overall, from a PYD perspective, the empirical findings provide important indicators that differentiate Roma youth from other minorities. The last two chapters of this part are devoted 
to highlighting the importance of (a) further exploration of youth development initiatives in Roma culture, and (b) multicultural principles relevant to consider in the Roma youth context.

The strength of this book lies in its exclusive focus on the historically marginalized Roma youth, in addition to an intentional acknowledgment of how an intersection of both intrinsic and systemic factors (school, family, community, peers, teachers, etc.) contribute to PYD in this minority culture. Moreover, several authors in this book, by sharing a commentary on wider applicability of the Roma case to other minority groups, have provided a useful model that can be further tested and evaluated by experts in PYD as applied to a cross-cultural context in particular.

Alongside these strengths, a few limitations of the body of available research on Roma youth are worth noting for future PYD scholars. First, the inclusion and exploration of additional PYD variables is warranted, such as classroom climate, prejudice and stigma experiences, mental health, and risky behaviors. In addition, other geographic locations with Roma population need to be studied (e.g., Canada, Asia). Methodologically speaking, longitudinal studies may contribute significantly to the emerging literature on Roma culture, across the lifespan. In sum, the book serves as an asset to students, practitioners, researchers, and policy makers from diverse fields of developmental science, human development, cross-cultural psychology, sociology, and social work and anyone who is especially curious to simply learn about the lesserknown Roma culture and its people.

\section{References}

Dimitrova, R., Sam, D. L., \& Ferrer-Wreder, L. (Eds.). (2021a). Roma minority youth across cultural contexts: Taking a positive approach to research, policy, and practice. Oxford University Press.

Dimitrova, R., Sam, D. L., \& Ferrer-Wreder, L. (2021b). Introduction. In R. Dimitrova, D. L. Sam, \& L. Ferrer-Wreder (Eds.), Roma minority youth across cultural contexts: Taking a positive approach to research, policy, and practice (pp. xv-xxiv). Oxford University Press.

Lerner, R. M. (2021). Foreword. In R. Dimitrova, D. L. Sam, \& L. Ferrer-Wreder (Eds.), Roma minority youth across cultural contexts: Taking a positive approach to research, policy, and practice (pp. ix-xii). Oxford University Press. 